\title{
Th2-associated immunity to bacteria in teenagers and susceptibility to asthma
}

\author{
E.M. Hollams*, B.J. Hales*, C. Bachert ${ }^{*}$, W. Huvenne* , F. Parsons*, N.H. de Klerk*, \\ M. Serralha*, B.J. Holt*, S. Ahlstedt", W.R. Thomas*, P.D. Sly* and P.G. Holt*
}

ABSTRACT: Bacterial colonisation of the airways is associated with increased risk of childhood asthma. Immunoglobulin (Ig)E against bacterial antigens has been reported in some asthmatics, suggesting a role for bacterial-specific type-2 immunity in disease pathogenesis. We aimed to investigate relationships between bacterial-specific IgE amongst teenagers and asthma susceptibility.

We measured titres of IgE against Haemophilus influenzae, Streptococcus pneumoniae and Staphylococcus aureus in 1,380 teenagers, and related these to asthma symptomatology and immunophenotypes.

IgE titres against $S$. aureus-derived enterotoxins were highest amongst atopics and were associated with asthma risk. Surprisingly, IgE titres against $H$. influenzae and $S$. pneumoniae surface antigens were higher, not stratified by atopy and independently associated with decreased asthma risk.

The positive association between type-2 immunity to $S$. aureus and asthma phenotypes probably reflects IgE-mediated effector cell activation via enterotoxin super antigens which are secreted in soluble form. The contrasting benign nature of type-2 immunity to $H$. influenzae and $S$. pneumoniae antigens may reflect their lower availability in soluble forms that can crosslink IgE receptors. We theorise that instead they may be processed by antigen presenting cells and presented to type-2 memory cells leading to mucosal secretion of interleukin (IL)-4/IL-13, a mechanism widely recognised in other tissues to attenuate T-helper-1 associated bacterialinduced inflammation.

KEYWORDS: Asthma, bacteria, bronchial hyperresponsiveness, immunoglobulin E, Raine study, Staphylococcal enterotoxin

ower respiratory tract infections have been linked in many studies to the development and expression of asthma during childhood, especially amongst atopics [1]. The primary focus has been upon viruses, particularly rhinovirus $[2,3]$, and bystander airway tissue damage during host-antiviral responses is widely believed to play a key role in driving wheezing disease pathogenesis towards chronicity. Considerably less attention has been paid to bacteria, with the exception of Staphylococcus aureus (SA) strains which produce soluble enterotoxins. These molecules function as superantigens and can directly activate a large proportion of peripheral T-cells [4], triggering polyclonal production of both T-helper (Th) 1 and Th2 cytokines and synthesis of enterotoxinspecific immunoglobulin (Ig)E. Colonisation with superantigen-producing SA has been suggested to play a role in a range of atopy-associated diseases, including atopic dermatitis [5], rhinosinusitis and allergic rhinitis [6, 7], as well as adult asthma [8,9] and childhood wheeze [10]. Recently, colonisation of the upper airways during early childhood with bacterial pathogens, including nonenterotoxin-producing strains, has been linked with subsequent development of persistent asthma [11], but the pathogenic mechanisms are unknown and the interpretation of these findings remains controversial [12].

The presence of underlying type-2 immune responses to nonenterotoxin-producing bacteria in asthmatics, in particular bacterial-specific $\operatorname{IgE}$, has been known for some time [13, 14]. Moreover these responses have recently been shown to be markedly increased following severe asthma

\section{AFFILIATIONS}

${ }^{\star}$ Telethon Institute for Child Health Research, Centre for Child Health Research, University of Western Australia, Perth, Australia,

\#Upper Airway Research Laboratory (URL), Dept of Otorhinolaryngology, Ghent University Hospital, Ghent, Belgium, and

"Centre for Allergy Research, National Institute of Environmental Medicine, Karolinska Institute, Stockholm, Sweden.

\section{CORRESPONDENCE}

P.G. Holt

Division of Cell Biology

Telethon Institute for Child Health Research

P0 Box 855

West Perth

WA 6872

Australia

E-mail: patrick@ichr.uwa.edu.au

Received:

Nov 192009

Accepted after revision:

Jan 142010

First published online:

Jan 282010 
exacerbations in children [15] suggesting that antigens from these bacteria gain entrance to the immune system via the inflamed airway mucosa. The significance of these findings is unclear, and more detailed investigations of relationships between host immune responses, including $\operatorname{IgE}$, to different classes of mucosal dwelling bacteria and susceptibility to asthma are needed. In particular, there is a requirement for baseline data on the spectrum of IgE responsiveness to bacteria in the normal population. Herein, we report on $\operatorname{IgE}$ responses to three potential bacterial pathogens, Haemophilus influenzae (HI), Streptococcus pneumoniae (SP) and enterotoxin-producing $\mathrm{SA}$, in a community cohort of 1,380 teenagers, and the positiveand negative-risk associations between antibody titres and underlying asthma-associated clinical phenotypes.

\section{MATERIAL AND METHODS}

\section{Study subjects}

The West Australian Pregnancy Cohort study (Raine Study) is a longitudinal birth cohort; mothers were enrolled from antenatal clinics from the main tertiary maternity hospital in Perth, Western Australia, and were not selected on any criteria other than having enrolled for antenatal care at the hospital [16]. Analyses presented here were based on data collected at the 14-yr follow-up of this cohort, and did not utilise information collected at other ages. By studying asthma in 14-yr-old children we are biasing towards asthma that is more closely associated with atopy and more likely to persist into adult life. All aspects of the current study were approved by our institutional human ethics committee (Princess Margaret Hospital Ethics Committee, Princess Margaret Hospital, Subiaco, Perth, Australia) and parents gave written consent, with assent given by the teenagers.

\section{Clinical phenotyping}

Current asthma was defined as wheeze or cough without a cold in the last 12 months, plus use of any asthma medication in the last 12 months in children with a doctor diagnosis of asthma ever. Current rhinoconjunctivitis was assessed on the basis of parental response to a standardised questionnaire regarding the child's symptoms (runny, blocked or itchy nose in the presence of runny or itchy eyes) over the preceding 12 months.

All spirometry measurements were performed in the morning (10:00-12:00 h) and conducted according to American Thoracic Society guidelines with the subjects seated [17]. Standard variables, forced vital capacity (FVC), forced expiratory volume in $1 \mathrm{~s}$ (FEV1), forced expiratory flow at $25-75 \%$ of FVC and FEV1/FVC were calculated.

Subjects were eligible to participate in methacholine (MCh) challenge testing if they obtained reproducible spirometry, had an FEV1 $\geqslant 80 \%$ of predicted, had no respiratory illness in the last 14 days and had withheld from their asthma medications for the standard period [17]. MCh challenges were performed with a Koko ${ }^{\circledR}$ digidoser (nSpire Health Inc., Longmont, CO, USA) using a modified dosimeter technique [18]. Subjects were given an initial saline dose followed by doubling doses of $\mathrm{MCh}$ $\left(0.0625,0.125,0.25,0.5,1,2,4\right.$ and $\left.8 \mathrm{mg} \cdot \mathrm{mL}^{-1}\right)$ delivered via DeVilbiss 646 nebulisers (DeVilbiss Healthcare, Somerset, PA, USA). Testing was stopped once a patient's FEV1 had fallen by $\geqslant 20 \%$ or the highest dose was administered. The doseresponse slope was calculated as the two-point slope of the curve regardless of the fall in FEV1 [19].

Lung function was represented in the statistical analysis by the FEV1/FVC ratio. In a community population of adolescents where restrictive lung disease would be unexpected, this ratio is most likely to represent airway obstruction in a manner that is independent of body habitus, lung size and sex.

\section{Immunological phenotyping}

Atopic family history was obtained from the questionnaire completed by the primary caregiver. Questions were asked about first-degree relatives (biological mother, biological father or sibling) seeking information about asthma, eczema, rhinoconjunctivitis and other allergies. Parents were asked to provide information about whether the allergies had been confirmed and by whom. Information was recorded separately about maternal and paternal allergic history. A child was considered to have a positive family history if one or more first-degree relatives had confirmed asthma, eczema or rhinoconjunctivitis.

Current atopic status, including serum titres of allergen-specific $\operatorname{IgE}$, was determined as detailed previously [20]. Subjects were considered to be atopic if they had total $\mathrm{IgE}$ of $\geqslant 300 \mathrm{kU} \cdot \mathrm{L}^{-1}$ and/ or specific IgE of $\geqslant 0.35 \mathrm{kU} \cdot \mathrm{L}^{-1}$ for any of the following allergens: house dust mite (HDM), rye grass pollen, cat, couch grass, mould mix, peanut or food mix. Total IgE as well as specific IgE to HDM (Dermatophagoides pteronyssinus), rye grass pollen (Lolium perenne), cat, couch grass (Cynodon dactylon), mould mix (Penicillium notatum, Cladosporium herbarum, Aspergillus fumigatus, Candida albicans, Alternaria alternata and Helminthosporium halodes), peanut and food mix (egg white, milk, fish, wheat, peanut and soybean) and to a mixture of SA enterotoxins (SAE) (Staphylococcal enterotoxin A, Staphylococcal enterotoxin B and toxic shock syndrome toxin 1), were measured by ImmunoCAP (Phadia AB, Uppsala, Sweden) [8].

$\mathrm{IgE}$ antibodies to outer membrane protein $\mathrm{P} 6$ and pneumococcal surface protein C (PspC) from HI and SP, respectively, were assayed by modifications to the procedure described to use humanised IgE antibody for absolute quantitation [21]. A microtitre plate dissociation-enhanced immunofluoresence assay (DELFIA ${ }^{\mathrm{TM}}$ ) was performed where antigen coating was standardised by capturing His-tagged recombinant antigens with anti-His monoclonal antibody coated as described previously [22]. The assay was calibrated by interpolating the results from a titration curve constructed with recombinant Derp2 captured by the same procedure and a standardised $\left(\mathrm{IU} \cdot \mathrm{mL}^{-1}\right.$ ) humanised IgE anti-Derp2 (Indoor Biotechnolgies, Charlottesville, VA, USA). The lower limit of detection was $0.1 \mathrm{ng} \cdot \mathrm{mL}^{-1}\left(0.041 \mathrm{kU} \cdot \mathrm{L}^{-1}\right)$ for P6 and PspC. The P6 antigen was prepared as described previously [15] and the PspC (aa 1 to 445) antigen as previously described by BROOKS-WALTER et al. [23].

Peripheral blood mononuclear cells (PBMC) were cryopreserved and subsequently cultured as described previously [20]. PBMC were cultured for $48 \mathrm{~h}$ in AIM-V medium with $4 \times 10^{-5} \mathrm{M}$ 2-mercaptoethanol alone or with $200 \mathrm{ng} \cdot \mathrm{mL}^{-1}$ Staphylococcal enterotoxin B (SEB; Sigma-Aldrich, Castle Hill, Australia). $0.6 \times 10^{6}$ cells were cultured in round-bottomed 96-well plates (Nunc, Roskilde, Denmark) at a concentration of $1.2 \times 10^{6}$ cells $\cdot \mathrm{mL}^{-1}$. 
Measurements of cytokines and other inflammatory mediators are as detailed previously [20] and in the supplementary material.

\section{Statistical analyses}

Univariate analysis of group differences in $\operatorname{IgE}$ titres were examined using the Mann-Whitney U-test, and bivariate relationships were assessed using Spearman's correlation. Continuous variables were $\log _{10}$ transformed for use in regression analyses. To allow $\log _{10}$ transformation, cytokine delta values $\leqslant 0$ were converted to 0.01 ; antibody values below the limits of detection were ascribed a value equivalent to half the limit of detection. Variables in multivariate analyses were selected based on univariate association with outcome at $\mathrm{p}<0.10$. Bronchial hyperresponsiveness (BHR) dose slope was analysed with linear regression, asthma risk and BHR risk with logistic regression, and asthma severity with ordinal regression. Analyses were performed using SPSS software (SPSS Inc., Chicago, IL, USA).

\section{RESULTS}

\section{IgE responses to SAE in atopic and non-atopic teenagers}

$\operatorname{IgE}$ responses against SAE are common amongst teenagers (19.3\% of cohort; table 1 in supplementary material) and more frequent amongst atopics ( $26.8 \%$ versus $8.0 \%$ in non-atopics).
Moreover as shown in figure 1a the mean SAE-IgE titres were also preferentially increased amongst atopics, suggesting that responsiveness is linked to the atopic phenotype. This gradation is similar if results are expressed as percentage with IgE titres above assay detection limits $(52.7 \%$ versus $22.3 \%$ respectively; table 1 supplementary material).

\section{SAE-IgE and risk for asthma}

Figure $1 \mathrm{~b}$ shows SAE-specific IgE titres within the cohort after stratification by atopy and clinical phenotype, and demonstrates the consistent relationship between SAE-IgE titre and the presence of respiratory symptoms in atopics. Further analysis by univariate logistic regression (table 1) confirmed this association. In particular, when we stratified by atopy status SAE-IgE was a significant risk factor amongst atopics for asthma and BHR, while amongst non-atopics SAE-IgE was only a risk factor for BHR. Figure. 1c further examines relationships between SAE-specific IgE and asthma. For this analysis the population was grouped on the basis of serum SAE-IgE levels (undetectable plus population terciles amongst responders), and asthma risk was computed for each group by univariate logistic regression; this risk appears to increase progressively with antibody titre. This association was explored further via logistic regression modelling, focusing
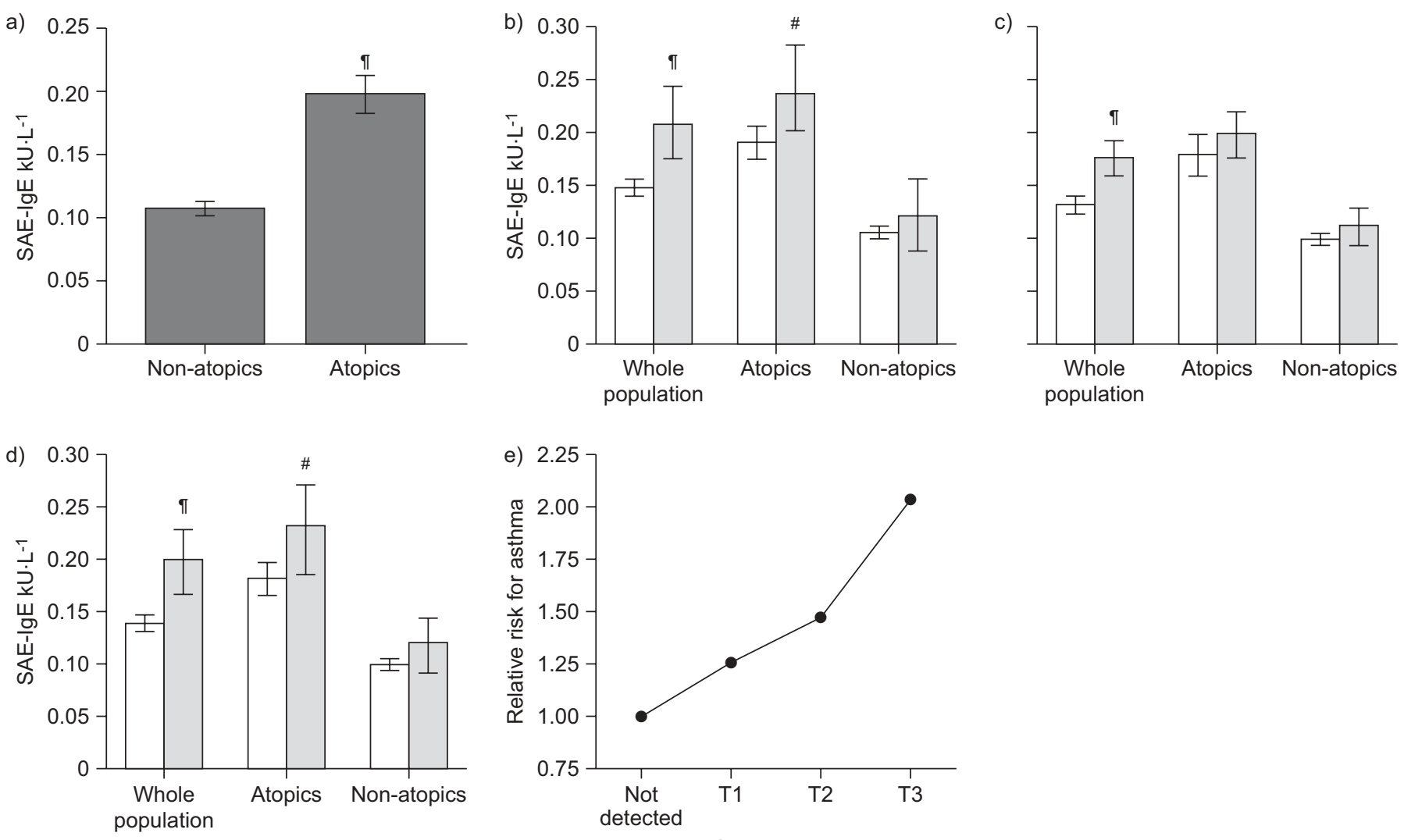

SAE-lgE titre

FIGURE 1. Staphylococcus aureus enterotoxin (SAE)-immunoglobulin (Ig)E titres within subgroups of the cohort. a) Data shown are geometric means (95\% Cl) of SAEIgE titres stratified by atopy. b, c, d) Data shown are geometric means $(95 \% \mathrm{Cl})$ of SAE-lgE titres stratified by clinical outcomes in b) asthma, C) rhinoconjunctivitis and d) bronchial hyperresponsiveness in the whole population and atopic and non-atopic subgroups. $\square$ : disease not present; 1 : disease present. e) Subjects with detectable SAE-IgE titres were split into terciles according to SAE-IgE: T1: $0.15-0.23 \mathrm{kU} \cdot \mathrm{L}^{-1} ; \mathrm{T} 2: 0.24-0.50 \mathrm{kU} \cdot \mathrm{L}^{-1} ; \mathrm{T} 3: 0.51-30.9 \mathrm{kU} \cdot \mathrm{L}^{-1}$. Risk of asthma was computed from univariate logistic regression and presented as mean risk of asthma amongst subjects in each tercile relative to subjects with undetectable SAE-IgE titres. $p=0.000$. Comparisons between groups (a-d) were assessed by Mann-Whitney U-test. ${ }^{\#}: p \leqslant 0.05 ; ": p \leqslant 0.005$. 


\begin{tabular}{|c|c|c|c|c|}
\hline \multirow[t]{2}{*}{ Clinical outcome } & \multirow[t]{2}{*}{ Cohort subgroup } & \multirow[t]{2}{*}{ Subjects } & \multicolumn{2}{|c|}{ SAE-IgE } \\
\hline & & & OR (95\% Cl) & $\mathrm{p}$-value \\
\hline Asthma & Whole population & $1337(140)$ & $1.95(1.39-2.76)$ & $<0.001$ \\
\hline \multirow[t]{3}{*}{ Rhinoconjunctivitis } & Whole population & $1336(527)$ & $1.93(1.50-2.48)$ & $<0.001$ \\
\hline & Atopics & 798 (413) & $1.21(0.91-1.62)$ & 0.188 \\
\hline & Non-atopics & $537(114)$ & $1.79(0.93-3.44)$ & 0.080 \\
\hline \multirow[t]{2}{*}{ BHR } & Whole population & $1286(236)$ & $2.06(1.54-2.76)$ & $<0.001$ \\
\hline & Atopics & 767 (182) & $1.53(1.11-2.12)$ & 0.010 \\
\hline
\end{tabular}

Data for subjects are presented as total cases in analysis (cases positive for clinical outcome). Odds ratio is per $\log _{10}\left(\mathrm{KU} \cdot \mathrm{L}^{-1}\right)$. BHR: bronchial hyperresponsiveness.

on the atopics identified in table 1 as the "at risk" group. In addition to bacterial-specific IgE titres, these analyses utilised a range of data derived from the study cohort relating to respiratory, inflammatory and atopy-associated functions [20]. A two-step process was undertaken as shown in table 2. First, univariate logistic regression was performed to identify individual asthma risk variable, including a range related to intensity of underlying atopy. Of note, SAE-specific cytokine responses (interleukin (IL)-5, IL-10 and IL-13) were also included. The final multivariate regression model combined these significant variables, as shown in table 2 . The list of variables identified as independently associated with asthma risk was dominated by measures related directly or indirectly to conventional atopy, notably aeroallergen-specific $\operatorname{IgE}$ and a marker of eosinophil activation. The IgE component of the SAE response did not remain as a significant risk variable but was supplanted by the SAE-specific cytokine response in the form of IL-10.

TABLE 2 Logistic regression modelling of risk for asthma in atopics

\begin{tabular}{|c|c|c|c|c|}
\hline \multirow[t]{2}{*}{ Log of variables } & \multicolumn{2}{|c|}{ Univariate regression } & \multicolumn{2}{|c|}{ Multivariate regression } \\
\hline & p-value & OR (95\% Cl) & p-value & OR $(95 \% \mathrm{Cl})$ \\
\hline SAE-IgE & 0.048 & $1.47(1.01-2.16)$ & NS & \\
\hline HDM-IgE & $<0.001$ & $1.71(1.44-2.03)$ & 0.002 & $1.40(1.14-1.72)$ \\
\hline Cat-IgE & $<0.001$ & $1.53(1.25-1.87)$ & NS & \\
\hline Mould-IgE & 0.040 & $1.21(1.01-1.45)$ & NS & \\
\hline Total IgE & 0.001 & $1.87(1.30-2.70)$ & NS & \\
\hline Atopic family history ${ }^{\#}$ & $<0.001$ & $4.47(2.13-9.38)$ & 0.002 & $3.71(1.61-8.55)$ \\
\hline Eczema $^{\#}$ & 0.059 & $1.70(0.98-2.94)$ & NS & \\
\hline Rhinoconjunctivitis ${ }^{\#}$ & $<0.001$ & $2.88(1.85-4.49)$ & 0.011 & $1.98(1.17-3.36)$ \\
\hline $\mathrm{FEV}_{1} / \mathrm{FVC}^{\#}$ & 0.004 & $0.96(0.94-0.99)$ & NS & \\
\hline BHR dose slope $\#$ & $<0.001$ & $4.46(2.91-6.83)$ & $<0.001$ & $3.21(1.98-5.20)$ \\
\hline Eosinophils & $<0.001$ & $4.58(2.24-9.37)$ & NS & \\
\hline Neutrophils & 0.045 & $0.36(0.13-0.98)$ & NS & \\
\hline Eosinophil protein $X$ & $<0.001$ & $6.37(2.84-14.28)$ & 0.002 & $4.65(1.78-12.11)$ \\
\hline SEB induced IL-5 & 0.033 & $1.98(1.06-3.71)$ & NS & \\
\hline SEB induced IL-10 & 0.011 & $2.56(1.24-5.28)$ & 0.006 & $3.43(1.42-8.30)$ \\
\hline SEB induced IL-13 & 0.011 & $3.08(1.29-7.34)$ & NS & \\
\hline
\end{tabular}

Univariate regression analysis utilised measures of total and specific immunoglobulin (lg)E (house dust mite (HDM), rye, cat, couch grass and mould), sex, body mass index, presence of eczema and/or rhinoconjunctivitis, lung function (forced expiratory volume in $1 \mathrm{~s}$ (FEV1)/forced vital capacity (FVC) ratio and bronchial hyperresponsiveness (BHR) dose slope), blood eosinophil and neutrophil numbers, urinary eosinophil protein $\mathrm{X}$, prostaglandin $\mathrm{F}_{2} \mathrm{a}$, soluble $\mathrm{CD} 14$ and responses of peripheral blood mononuclear cells to Staphylococcal enterotoxin B (SEB) which elicited moderate to high level cytokine production (interleukin (IL)-5, IL-10, IL-13 and interferon- $\gamma$ ) in all members of the cohort with available data. Only significant variables are shown and included in multivariate regression; the sample comprised 94 asthmatics and 547 nonasthmatics. SAE: Staphylococcus aureus enterotoxin; NS: not significant. * : variable not log ${ }_{10}$-transformed. 
TABLE 3 Multiple linear regression for bronchial hyperresponsiveness dose slope

\begin{tabular}{|c|c|c|c|c|c|c|c|c|}
\hline \multirow[t]{2}{*}{ Variables } & \multicolumn{4}{|c|}{ Atopic } & \multicolumn{4}{|c|}{ Non-atopic } \\
\hline & p-value & $\beta$ & SE & $t$ & $\mathrm{p}$-value & $\beta$ & SE & $\mathbf{t}$ \\
\hline SAE-IgE & NS & & & & 0.005 & 0.149 & 0.052 & 2.8 \\
\hline HDM-IgE & $<0.001$ & 0.096 & 0.013 & 7.5 & NR & & & \\
\hline Mould-IgE & 0.033 & 0.034 & 0.016 & 2.1 & NR & & & \\
\hline Eosinophil protein $X$ & 0.007 & 0.185 & 0.068 & 2.7 & NR & & & \\
\hline Males ${ }^{\#}$ & $<0.001$ & -0.235 & 0.036 & -6.6 & $<0.001$ & -0.141 & 0.030 & -4.7 \\
\hline Atopic family history ${ }^{\#}$ & 0.040 & 0.080 & 0.039 & 2.1 & NR & & & \\
\hline SEB IL-5 & 0.002 & 0.102 & 0.033 & 3.1 & NR & & & \\
\hline
\end{tabular}

Variables included in regression were significant in univariate analysis. $\beta$ : standardised correlation coefficient; $\mathrm{t}$; $\beta$ divided by SE; SAE: Staphylococcus aureus enterotoxin; Ig: immunoglobulin; FEV1; forced expiratory volume in 1 s; FVC: forced vital capacity; SEB: Staphylococcal enterotoxin B; IL: interleukin; NR: not in regression; NS: not significant. \#: not $\log _{10}$-transformed.

\section{SAE-IgE and risk for BHR}

A potential association between SAE-IgE responses and risk for BHR development is also suggested by the results in table 1. Accordingly, multivariate linear regression analyses to predict BHR dose slope were performed employing variables that were significant in initial univariate regressions. In contrast to asthma, univariate analyses showed that SAE-IgE was a risk factor for BHR for both non-atopic and atopic subjects (table 2 in supplementary material), so these were assessed separately in multivariate analyses. Within the atopic population SAE-IgE does not survive as a significant risk factor for BHR in the multivariate model (table 3); however, IL-5 responsiveness to SAE displays a strong positive correlation with degree of BHR. In contrast, SAE-IgE survives as an independent risk factor in the non-atopic subjects.

\section{IgE responses to $\mathrm{HI}$ and SP antigens and risk for respiratory symptoms}

The spectrum of IgE titres to HI P6 and SP PspC antigens within the study cohort are shown in figure $2 \mathrm{a}$ and table 1 in the supplementary material. IgE responses to these antigens are more frequent and stronger than those against SAE and, in contrast to the pattern seen for SAE, the atopic and non-atopic subpopulations display comparable responses to P6 and PspC. Moreover, $\operatorname{IgE}$ responses to these antigens are strongly intercorrelated within both atopics (rho 0.658; $\mathrm{p}=0.000$ ) and non-atopics (rho 0.623; $\mathrm{p}=0.000$ ) but are unrelated to responses to SAE (table 3 in supplementary material).

Univariate analyses on the whole population stratified by P6and PspC-IgE titre (fig. $2 b$ ) and by atopic status (table 4) revealed relationships markedly different from those observed for SAE-IgE. In particular, IgE titres against these nonenterotoxin antigens associated inversely with asthma risk (fig. $2 \mathrm{~b}$ versus fig. $1 \mathrm{c}$, and table 4 versus table 1 ). Of note, amongst the atopics both P6-IgE and PspC-IgE remained as significant protective factors in relation to asthma risk in multivariate analyses, which included allergen specific $\operatorname{IgE}$ measures as confounders (table 5).
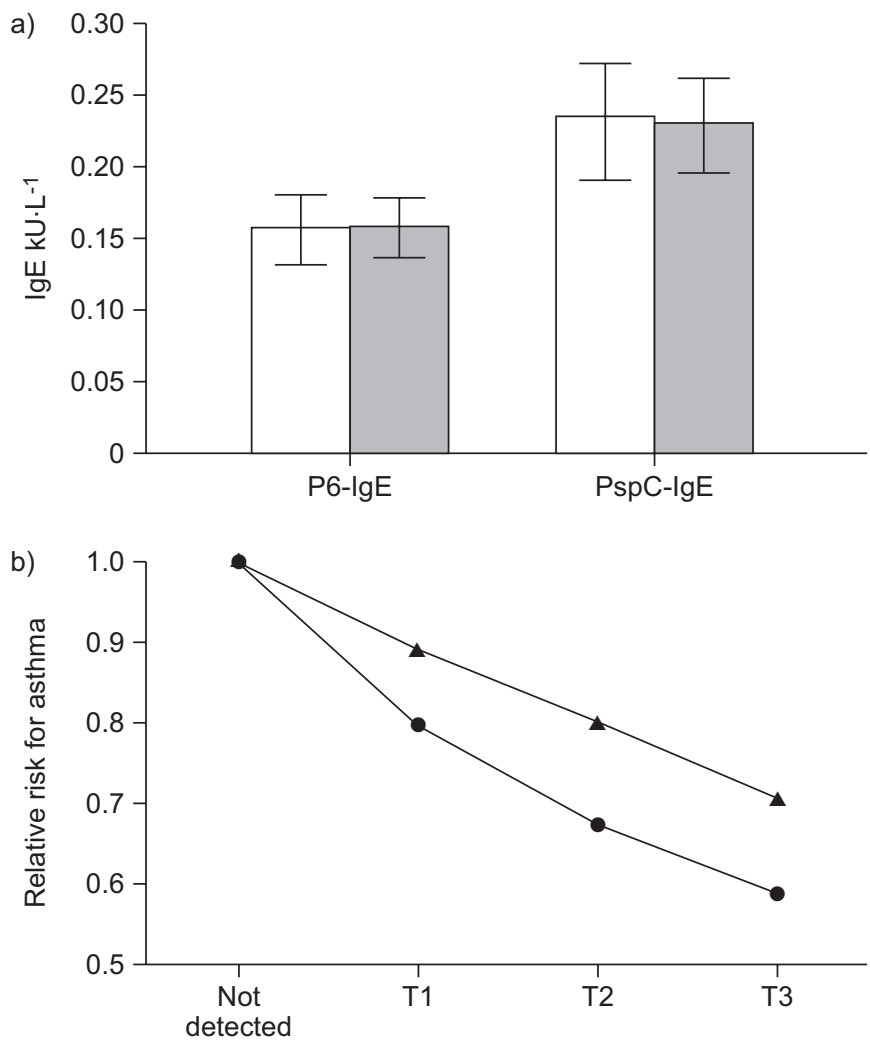

Specific lgE titre

FIGURE 2. Outer membrane protein P6 (P6)-immunoglobulin (Ig)E and pneumococcal surface protein C (PspC)-lgE titres within subgroups of the cohort. a) Geometric means $(95 \% \mathrm{Cl}$ ) of specific IgE titres are shown for the atopic ( $\square$ ) and non-atopic subgroups $(\square)$. Comparison by Mann-Whitney U-test found no significant difference between titres for atopic and non-atopic subgroups. b) Subjects were split into terciles on the basis of detectable PspC-IgE $(\bullet)$ (T1: 0.04$\left.0.65 \mathrm{kU} \cdot \mathrm{L}^{-1} ; \mathrm{T} 2: 0.66-1.78 \mathrm{kU} \cdot \mathrm{L}^{-1} ; \mathrm{T} 3: 1.79-12.67 \mathrm{kU} \cdot \mathrm{L}^{-1}\right)$ and P6-IgE titre $(\mathbf{\Delta})(\mathrm{T} 1$ : $\left.0.04-0.29 \mathrm{kU} \cdot \mathrm{L}^{-1} ; \mathrm{T} 2: 0.30-0.99 \mathrm{kU} \cdot \mathrm{L}^{-1} ; \mathrm{T} 3: 1.00-15.51 \mathrm{kU} \cdot \mathrm{L}^{-1}\right)$. Univariate logistic regression models employing PspC-IgE and P6-IgE titres were used to calculate risk of asthma, which are presented as mean risks amongst subjects in each tercile relative to subjects with undetectable IgE-titres. P6: $p=0.080$; PspC: $p=0.006$. 
TABLE 4 Outer membrane protein P6-immunoglobulin (Ig)E and PspC-IgE titres and disease risk: univariate logistic regression

\begin{tabular}{|c|c|c|c|c|c|c|}
\hline \multirow[t]{2}{*}{ Clinical outcome } & \multirow[t]{2}{*}{ Cohort subgroup } & \multirow[t]{2}{*}{ Subjects } & \multicolumn{2}{|c|}{ P6-IgE } & \multicolumn{2}{|c|}{ PspC-IgE } \\
\hline & & & OR $(95 \% \mathrm{Cl})$ & p-value & OR (95\% Cl) & $p$-value \\
\hline \multirow[t]{3}{*}{ Asthma } & Whole population & $1337(140)$ & $0.82(0.66-1.02)$ & 0.080 & $0.76(0.62-0.92)$ & 0.006 \\
\hline & Atopics & 799 (113) & $0.75(0.59-0.97)$ & 0.027 & $0.73(0.58-0.91)$ & 0.006 \\
\hline & Non-atopics & $537(27)$ & $1.14(0.70-1.84)$ & 0.606 & $0.86(0.56-1.33)$ & 0.498 \\
\hline Rhinoconjunctivitis & Non-atopics & $537(114)$ & $0.92(0.71-1.20)$ & 0.554 & $1.10(0.87-1.38)$ & 0.440 \\
\hline \multirow[t]{3}{*}{ BHR } & Whole population & $1286(236)$ & $1.09(0.92-1.30)$ & 0.308 & $1.11(0.95-1.30)$ & 0.193 \\
\hline & Atopics & 767 (182) & $1.11(0.91-1.35)$ & 0.312 & $1.17(0.97-1.42)$ & 0.092 \\
\hline & Non-atopics & $518(54)$ & $1.03(0.73-1.47)$ & 0.866 & $0.95(0.69-1.30)$ & 0.745 \\
\hline
\end{tabular}

Data for subjects is presented as total cases in analysis (cases positive for clinical outcome). PspC: pneumococcal surface protein C; NHR: bronchial hyperresponsiveness. OR is per $\log _{10}\left(k U \cdot L^{-1}\right)$.

\section{DISCUSSION}

The most intensively studied bacteria in relation to pathogenesis of inflammatory airway diseases are enterotoxin-producing SA. Their secreted products can trigger production of T-cell cytokines including IL-5, IL-10, IL-13 and interferon- $\gamma$ [24, 25], and can also lead to inhibition of T-regulatory cell activity [26].

In this cohort IgE responses to SAE were higher and more frequent amongst atopics, in particular those with airway symptoms (fig. 1a). Moreover, in univariate models SAEspecific IgE titre was a significant risk factor for asthma and BHR, particularly amongst atopics (table 1). SAE-IgE titres in atopics correlate strongly with those against conventional aeroallergens and total IgE (data not shown), and the SAE-IgE effects in these subjects relating to asthma risk were no longer significant after adjusting for overall $\operatorname{IgE}$ levels and the potential confounders identified in initial univariate analyses (table 2). This suggests that the direct disease promoting effects of IgE against SAE may be secondary to those resulting from IgE against the common aeroallergens, and/or may be restricted to subjects with severe wheeze as suggested previously [8-10]. Alternatively, SAE-IgE may be a surrogate for other covert aspects of the Th2-associated response to SAE, including the effects of SAE on polyclonal stimulation of IgE production and/or on $\operatorname{IgE}$ independent mechanisms. It is pertinent to note earlier findings that T-cells from a subset of atopic children are hyperresponsive to stimulation with the archetypal SEB [27, 28], which triggers cytokines including IL-5, IL-10 and IL-13. Accordingly, we included assessment of PBMC responses to SEB as part of the immunophenotyping of this cohort. As noted in table 2, SEB-induced IL-5, IL-10 and IL-13 responses were associated with asthma risk in atopics in univariate analyses, and inclusion of these variables in the final multivariate model identified the IL-10 component of the SEB response as an independent associate of asthma risk. Despite the anti-inflammatory action of this cytokine in relation to allergen-specific Th2 responses [29], its production in excess and/or in the wrong context has been associated with increased susceptibility to wheezing-related symptoms [20, 30]. Our findings are also consistent with a recent report linking

TABLE 5 Identification of asthma risk factors in atopics by multivariate logistic regression

\begin{tabular}{|c|c|c|c|c|}
\hline \multirow[t]{2}{*}{ Variables } & \multicolumn{2}{|c|}{ P6-IgE } & \multicolumn{2}{|c|}{ PspC-IgE } \\
\hline & OR $(95 \% \mathrm{Cl})$ & p-value & OR $(95 \% \mathrm{Cl})$ & p-value \\
\hline PspC-IgE & NR & & $0.75(0.57-0.98)$ & 0.034 \\
\hline HDM-IgE & $1.35(1.09-1.66)$ & 0.006 & $1.39(1.13-1.71)$ & 0.002 \\
\hline Rhinoconjunctivitis $^{\#}$ & $2.00(1.18-3.37)$ & 0.010 & $1.98(1.17-3.34)$ & 0.011 \\
\hline Eosinophil protein $X$ & NS & & $3.92(1.51-10.16)$ & 0.005 \\
\hline Atopic family history & $3.99(1.73-9.19)$ & 0.001 & $3.67(1.60-8.45)$ & 0.002 \\
\hline Eosinophils & $2.72(1.01-7.34)$ & 0.048 & NS & \\
\hline
\end{tabular}

Details of variables included in regressions are detailed in table 2 except Staphylococcal Enterotoxin B-induced cytokine responses. The sample comprised 95 asthmatics and 549 non-asthmatics. P6: outer membrane protein P6; Ig: immunoglobulin; PspC: pneumococcal surface protein C; HDM: house dust mite; BHR: bronchial hyperresponsiveness; NR: not in regression; NS: not significant. ${ }^{\#}$ : variable not $\log _{10}$ transformed. 
susceptibility to asthma symptoms following occupational lipopolysaccharide (LPS) exposure to levels of LPS-induced IL-10 production by PBMC [31].

The association between SAE-IgE and risk for BHR was further examined by multiple linear regression, incorporating potential confounders identified by univariate linear regression. As found for asthma, SAE-IgE was not a significant risk factor for BHR in atopic teenagers (table 3). However, this model does contain SEB-induced IL-5 which can drive eosinophilia, in addition to eosinophil protein $\mathrm{X}$, a product of activated eosinophils. Heightened eosinophil-related responses were previously identified as the strongest risk factor for wheeze and BHR in atopic school children [32].

In contrast to these findings relating to atopics, the positive association observed amongst non-atopics between BHR and SAE-IgE by univariate analysis (table 1) remained significant after adjustment for potential confounders by logistic regression (table 3). This suggests that SAE-specific IgE may function as an independent risk factor for BHR in non-atopics, implying that despite its low titre this IgE may contribute to airways inflammation in subjects in whom significant $\operatorname{IgE}$ of other specificities is extremely rare.

$\operatorname{IgE}$ antibodies to nasopharyngeal bacteria have been reported in a number of studies and a recent investigation detected a steep rise of anti-P6 IgE titres in children in the wake of severe asthma exacerbations [15], which implies that sufficient bacterial antigen penetrated the mucosa during this period to stimulate underlying bacterial-specific immunity. These responses are unlikely to be restricted to antibody, given that bacterial products exemplified by HI P6 antigen are also potent inducers of pro-inflammatory cytokines from human macrophages [33] including those at mucosae. Our findings do not identify the precise contribution of anti-bacterial Th2 immunity to the local cytokine milieu in the airways, but this contribution is clearly more complex than a straightforward addition to ongoing inflammation. In particular, HI- and SP-specific IgE is inversely associated with asthma risk in healthy atopic teenagers (table 4, fig. 2b) despite the fact that respective (mean) production levels are higher than corresponding responses to SAE which are positively associated with risk (fig. 1e versus fig. 2b). This discrepancy may be due, in part, to the active secretion of soluble SAE [34]. In contrast, PspC antigen of SP would be expected to be mainly encountered when covalently attached to the cell wall [35] and although HI do secrete vesicles that contain the outer membrane antigen P6 [36], these are 200-nm structures which may not be readily available for cross-linking IgE-FcR-armed receptors.

Additionally, the finding of circulating specific IgE antibody against HI and SP also automatically denotes the presence of additional forms of underlying Th2 immunity against these antigens. In particular, the presence of IL-4 and/or IL-13secreting Th cells [37]. Indeed, IL-13 production by HIstimulated PBMC from both atopics and non-atopics has been reported previously for P6 [38] and IL-4 production against other undefined antigens in $\mathrm{HI}$ extracts has also been reported [39]. It is noteworthy in this regard that IL-4 and IL-13 are highly pleiotrophic cytokines with multiple regulatory functions beyond $\operatorname{IgE}$ regulation, including an important role in modulation of macrophage activity. However, pre-treatment of macrophages with IL-4 can induce "alternative activation" leading to potentiation of cytokine responsiveness to subsequent microbial exposure [40]. Conversely, as demonstrated with human cells from a variety of sources including synovium, blood, peritoneum and the central nervous system [41-44], IL-4/IL-13 can also play an anti-inflammatory role via attenuation of bacterial-induced production of pro-inflammatory cytokines, such as tumour necrosis factor- $\alpha$, IL- 1 and IL- 6 by macrophages. Thus, P6-specific and PspC-specific Th2-memory cells of the type required for stimulation of $\mathrm{IgE}$ production could serve as an inducible source of such "homeostatic" IL-4/IL-13 in response to transmucosal leakage of these antigens and their uptake by local antigen presenting cells [45], thus helping to attenuate the pro-inflammatory effects of ligands released by the organisms. Follow-up studies are required to elucidate the potential dualistic nature of these poorly understood Th2 responses to mucosal dwelling bacteria.

\section{SUPPORT STATEMENT}

The authors are supported by the National Health and Medical Research Council of Australia (Canberra, Australia). The Raine Medical Research Foundation at the University of Western Australia (Perth, Australia) provided funding for the ongoing core Raine Study. Phadia Diagnostics (Uppsala, Sweden) provided the reagents for determination allergen-specific $\operatorname{IgE}$ antibody titres in the cohort.

\section{STATEMENT OF INTEREST}

Statements of interest for S. Ahlstedt and P.G. Holt and the study itself can be found at www.erj.ersjournals.com/misc/statements.dtl

\section{ACKNOWLEDGEMENTS}

We acknowledge with thanks the skilled technical assistance of J. Tizard, the study families and the members of the Raine Study team who participated. We thank Phadia Diagnostics (Uppsala, Sweden) for the gift of the reagents for determination allergen-specific IgE antibody titres in the cohort.

\section{REFERENCES}

1 Sly PD, Boner AL, Björksten B, et al. Early identification of atopy in the prediction of persistent asthma in children. Lancet 2008; 372: 1100-1106.

2 Jackson DJ, Gangnon RE, Evans MD, et al. Wheezing rhinovirus illnesses in early life predict asthma development in high-risk children. Am J Respir Crit Care Med 2008; 178: 667-672.

3 Message SD, Laza-Stanca V, Mallia P, et al. Rhinovirus-induced lower respiratory illness is increased in asthma and related to virus load and Th1/2 cytokine and IL-10 production. Proc Natl Acad Sci USA 2008; 105: 13562-13567.

4 Proft T, Fraser JD. Bacterial superantigens. Clin Exp Immunol 2003; 133: 299-306.

5 Leung DY, Boguniewicz M, Howell MD, et al. New insights into atopic dermatitis. J Clin Invest 2004; 113: 651-657.

6 Bachert C, Zhang N, Patou J, et al. Role of staphylococcal superantigens in upper airway disease. Curr Opin Allergy Clin Immunol 2008; 8: 34-38.

7 Lee JH, Lin YT, Yang YH, et al. Increased levels of serum-specific immunoglobulin $\mathrm{E}$ to staphylococcal enterotoxin a and $\mathrm{B}$ in patients with allergic rhinitis and bronchial asthma. Int Arch Allergy Immunol 2005; 138: 305-311.

8 Bachert C, Gevaert P, Howarth P, et al. IgE to Staphylococcus aureus enterotoxins in serum is related to severity of asthma. J Allergy Clin Immunol 2003; 111: 1131-1132. 
9 Hauk PJ, Wenzel SE, Trumble AE, et al. Increased T-cell receptor $\mathrm{v} \beta 8+\mathrm{T}$ cells in bronchoalveolar lavage fluid of subjects with poorly controlled asthma: a potential role for microbial superantigens. J Allergy Clin Immunol 1999; 104: 37-45.

10 Semic-Jusufagic A, Bachert C, Gevaert P, et al. Staphylococcus aureus sensitization and allergic disease in early childhood: populationbased birth cohort study. J Allergy Clin Immunol 2007; 119: 930-936.

11 Bisgaard $\mathrm{H}$, Hermansen MN, Buchvald F, et al. Childhood asthma after bacterial colonization of the airway in neonates. $N$ Engl J Med 2007; 357: 1487-1495.

12 von Mutius E. Of attraction and rejection-asthma and the microbial world. N Engl J Med 2007; 357: 1545-1547.

13 Pauwels R, Verschraegen G, van der Straeten M. IgE antibodies to bacteria in patients with bronchial asthma. Allergy 1980; 35: 665-669.

14 Tee RD, Pepys J. Specific serum IgE antibodies to bacterial antigens in allergic lung disease. Clin Allergy 1982; 12: 439-450.

15 Hales BJ, Martin AC, Pearce LJ, et al. Anti-bacterial IgE in the antibody responses of house dust mite allergic children convalescent from asthma exacerbation. Clin Exp Allergy 2009; 39: 1170-1178.

16 Newnham JP, Evans SF, Michael CA, et al. Effects of frequent ultrasound during pregnancy: a randomised controlled trial. Lancet 1993; 342: 887-891.

17 Standardization of spirometry, 1994 Update. American Thoracic Society. Am J Respir Crit Care Med 1994; 152: 1107-1136.

18 Crapo RO, Casaburi R, Coates AL. Guidelines for methacholine and exercise challenge testing-1999. Am J Respir Crit Care Med 2000; 161: 309-329.

19 O'Connor G, Sparrow D, Taylor D, et al. Analysis of dose-response curves to methacholine. An approach suitable for population studies. Am Rev Respir Dis 1987; 136: 1412-1417.

20 Hollams EM, Deverell M, Serralha M, et al. Elucidation of asthma phenotypes in atopic teenagers through parallel immunophenotypic and clinical profiling. J Allergy Clin Immunol 2009;124: 463470, 470 e1-e16.

21 Schuurman J, Perdok GJ, Lourens TE, et al. Production of a mouse/human chimeric IgE monoclonal antibody to the house dust mite allergen Der p 2 and its use for the absolute quantification of allergen-specific IgE. J Allergy Clin Immunol 1997; 99: 545-550.

22 Hales BJ, Bosco A, Mills KL, et al. Isoforms of the major peanut allergen Ara h 2: IgE binding in children with peanut allergy. Int Arch Allergy Immunol 2004; 135: 101-107.

23 Brooks-Walter A, Briles DE, Hollingshead SK. The pspC gene of Streptococcus pneumoniae encodes a polymorphic protein, PspC, which elicits cross-reactive antibodies to PspA and provides immunity to pneumococcal bacteremia. Infect Immun 1999; 67: 6533-6542.

24 Heaton T, Mallon D, Venaille T, et al. Staphylococcal enterotoxin induced IL-5 stimulation as a cofactor in the pathogenesis of atopic disease: the hygiene hypothesis in reverse? Allergy 2003; 58: 252-256.

25 Lehmann HS, Heaton T, Mallon D, et al. Staphylococcal enterotoxin-B-mediated stimulation of interleukin-13 production as a potential aetiologic factor in eczema in infants. Int Arch Allergy Immunol 2004; 135: 306-312.

$26 \mathrm{Ou} \mathrm{LS}$, Goleva E, Hall C, et al. T regulatory cells in atopic dermatitis and subversion of their activity by superantigens. J Allergy Clin Immunol 2004; 113: 756-763.

27 Rowe J, Heaton T, Kusel M, et al. High IFN-gamma production by CD8+ T cells and early sensitization among infants at high risk of atopy. J Allergy Clin Immunol 2004; 113: 710-716.
28 Sharp MJ, Rowe J, Kusel M, et al. Specific patterns of responsiveness to microbial antigens staphylococcal enterotoxin $\mathrm{B}$ and purified protein derivative by cord blood mononuclear cells are predictive of risk for development of atopic dermatitis. Clin Exp Allergy 2003; 33: 435-441.

29 Moore KW, O'Garra A, de Waal Malefyt R, et al. Interleukin-10. Annu Rev Immunol 1993; 11: 165-190.

30 Colavita AM, Hastie AT, Musani AI, et al. Kinetics of IL-10 production after segmental antigen challenge of atopic asthmatic subjects. J Allergy Clin Immunol 2000; 106: 880-886.

31 Smit LA, Heederik D, Doekes G, et al. Ex vivo cytokine release reflects sensitivity to occupational endotoxin exposure. Eur Respir J 2009; 34: 795-802.

32 Heaton $\mathrm{T}$, Rowe J, Turner $\mathrm{S}$, et al. An immunoepidemiological approach to asthma: identification of in-vitro T-cell response patterns associated with different wheezing phenotypes in children. Lancet 2005; 365: 142-149.

33 Berenson CS, Murphy TF, Wrona CT, et al. Outer membrane protein P6 of nontypeable Haemophilus influenzae is a potent and selective inducer of human macrophage proinflammatory cytokines. Infect Immun 2005; 73: 2728-2735.

34 Robbins R, Gould S, Bergdoll M. Detecting the enterotoxigenicity of Staphylococcus aureus strains. Appl Microbiol 1974; 28: 946-950.

35 Kadioglu A, Weiser JN, Paton JC, et al. The role of Streptococcus pneumoniae virulence factors in host respiratory colonization and disease. Nat Rev Microbiol 2008; 6: 288-301.

36 Lee EY, Bang JY, Park GW, et al. Global proteomic profiling of native outer membrane vesicles derived from Escherichia coli. Proteomics 2007; 7: 3143-3153.

37 Geha RS, Jabara HH, Brodeur SR. The regulation of immunoglobulin E class-switch recombination. Nat Rev Immunol 2003; 3: 721-732.

38 Epton MJ, Hales BJ, Thompson PJ, et al. T cell cytokine responses to outer membrane proteins of Haemophilus influenzae and the house dust mite allergens Der p 1 in allergic and non-allergic subjects. Clin Exp Allergy 2002; 32: 1589-1595.

39 King PT, Hutchinson PE, Johnson PD, et al. Adaptive immunity to nontypeable Haemophilus influenzae. Am J Respir Crit Care Med 2003, 167: 587-592.

40 Varin A, Mukhopadhyay S, Herbein G, et al. Alternative activation of macrophages by IL-4 impairs phagocytosis of pathogens but potentiates microbial-induced signalling and cytokine secretion. Blood 2010; 115: 353-362.

41 Clarke RM, Lyons A, O'Connell F, et al. A pivotal role for interleukin-4 in atorvastatin-associated neuroprotection in rat brain. J Biol Chem 2008; 283: 1808-1817.

42 Hart PH, Ahern MJ, Jones CA, et al. Synovial fluid macrophages and blood monocytes differ in their response to IL-4. J Immunol 1993; 151: 3370-3380.

43 Hart PH, Cooper RL, Finlay-Jones JJ. IL-4 suppresses IL-1 beta, TNF-alpha and PGE2 production by human peritoneal macrophages. Immunology 1991; 72: 344-349.

44 Hart PH, Vitti GF, Burgess DR, et al. Potential antiinflammatory effects of interleukin 4: suppression of human monocyte tumor necrosis factor alpha, interleukin 1, and prostaglandin E2. Proc Natl Acad Sci USA 1989; 86: 3803-3807.

45 Holt PG, Strickland DH, Wikstrom ME, et al. Regulation of immunological homeostasis in the respiratory tract. Nat Rev Immunol 2008; 8: 142-152. 